\title{
Investigating Peer Instruction: How the Initial Voting Session Affects Students' Experiences of Group Discussion
}

\author{
Kjetil L. Nielsen, Gabrielle Hansen-Nygård, and John B. Stav \\ Sør-Trøndelag University College, 7004 Trondheim, Norway \\ Correspondence should be addressed to Kjetil L. Nielsen, kjetil.l.nielsen@hist.no
}

Received 16 March 2012; Accepted 3 April 2012

Academic Editors: F. Jimenez, A. Kara, K. Kiewra, and K. Y. Kuo

Copyright (C) 2012 Kjetil L. Nielsen et al. This is an open access article distributed under the Creative Commons Attribution License, which permits unrestricted use, distribution, and reproduction in any medium, provided the original work is properly cited.

Peer Instruction is a popular method of implementation when using Student Response Systems (SRS) in classroom teaching. The students engage in peer discussion to solve conceptual multiple choice problems. Before discussion, students are given time to think and give individual responses with a voting device. In this paper, we investigate how this initial voting session affects students' experiences of the following discussion. The data is based on student interviews which were analyzed using analytical tools from grounded theory. The students emphasize the individual thinking period as crucial for constructing explanations, argumentation, and participation during discussions, and hence for facilitating learning. However, displaying the results from the initial vote can be devastating for the quality of the discussions, especially when there is a clear majority for a specific alternative. These findings are discussed in light of recent quantitative studies on Peer Instruction.

\section{Introduction}

The traditional one-way teacher style of lecturing can be effective when delivering factual content, but it is not as effective for facilitating cognitive skills $[1,2]$. Engaging students in active-learning activities can be an important factor for mastering skills such as critical thinking and problem solving $[1,3]$, skills that are often lacking in novice science students [4]. Although such skills are vital to evaluate scientific evidence and theories, students also have to be able to generate and present explanations and arguments for their evaluations, that is, to be fluent in the scientific language [5]. Novice students also suffer in that they are often unable to put into words, or at least scientific words, how they approach the use of theories to solve problems. Engaging students in peer discussions can challenge them to generate explanations and convincing arguments for their solution and in this way also facilitate deeper understanding of the scientific phenomena [5].

One way of engaging students in active-learning activities is to use a Student Response System (SRS). Such systems are often used during the lecture to present students with multiple choice questions, which they will discuss with their peers in small groups before answering with a voting device [6-10]. The result from the voting session is displayed in the form of a histogram which can give the teacher an indication of the level of understanding among the students and if they are able to follow the lecture $[10,11]$. SRS use in classroom teaching has been shown to increase learning [1215] including increased conceptual understanding in physics courses $[12,16,17]$.

Although SRS can be an outstanding tool for facilitating peer discussion, different choices of implementation can have a high impact on the quality of the discussions. For instance, giving credits for SRS participation has been shown to increase the overall participation in the class [18]. However, in a study by James [19], the researcher found that if each individual student was "punished" for voting incorrectly, that is, that he/she was not given as much credit as voting correctly, the group discussions tended to be dominated by students with greater knowledge while other students remained passive. If the students were only credited for participation, they would be more inclined to participate and explore different explanations and ideas.

One popular methodological implementation of SRS is with the Peer Instruction technique [17]. During the 
lecture students are presented with a problem, often where conceptual ideas are in focus, to challenge their knowledge about the subject as opposed to simply looking up the answer in the textbook. Students are given time to think on their own for about 2-3 minutes and answer individually before they are encouraged to engage in discussion with nearby students. The discussions are concluded with a revote and an explanation by the teacher. Dufresne et al. [11] describe a similar method, but where the initial voting session is omitted. Instead, students start discussing immediately after the question is presented and the group discussions are concluded with a class-wide discussion instead of teacher explanation.

In a comparative study between Peer Instruction and the method described by Dufresne et al. [11], students felt that without the initial voting session they would be more inclined to be passive in group discussions and that the discussions would be more likely to be dominated by confident and/or "stronger" students [20]. Students reported that they used the initial voting session to formulate their own answer, which they in turn could use in the following discussion, and that they therefore would be more likely to engage in dialogue and defend their views. The researchers argued that the lack of an individual thinking period before discussion would result in less cognitive conflict at the start of discussion and thus students would be more inclined to accept dominant explanations.

There have been several recent quantitative studies on different aspects of Peer Instruction [21-24]. Previous studies have shown that the amount of correct votes increases after the discussion $[16,25]$. One interpretation of these results could be that students choose the same as stronger students and not that they change their answer as a result of learning. In a study by Smith et al. [23], the researchers found evidence that the increase of correct votes is indeed a result of increased learning and not primarily due to the influence of other students. Even in groups where no students initially had the right answer, they observed an increase in learning. Smith et al. [24] showed that both the peer discussion and teacher explanation are important for facilitating learning with Peer Instruction. Excluding either the discussion or teacher explanation showed less learning than the combination of both.

A common practice when using Peer Instruction is to show students the results from the initial voting session prior to the group discussion [26]. Perez et al. [22] found that the probability of students switching to the alternative with the majority of votes increased by $30 \%$ if the results were displayed to the students. The researchers provided several interpretations for these findings. A clear majority could function as a stimulus for focused discussions and students might discover flaws in their original reasoning by trying to identify why most students chose one particular alternative. Another interpretation was that students simply switched to this alternative based on the consensus of nearby students. Confidence in their own choice has been shown to be significantly higher if students can see that they initially voted for an alternative in the majority [21]. This was persistent whether the alternative was correct or not.
The study in this paper was a part of EU-cofounded projects (EduMecca, Do-it, Done-it and Global-SRS) at SørTrøndelag University College in Trondheim, Norway. One goal of these projects was to develop an online SRS designed for effective classroom teaching, where students can use their own mobile device, such as smart-phones, as a voting device as compared to the traditional "clickers". As well as evaluating the system from a technical point of view, we also investigated different methodological implementations. More information about these projects can be found at our web page (http://www.histproject.no/).

The inspiration for this study was the findings of Nicol and Boyle [20]. We wanted to go deeper into, and try to examine, the effects of the initial voting session (and thinking period) with Peer Instruction. To do so, we divided the study into two parts: a quantitative part based on survey data and video of students engaged in peer discussion during class and a pure qualitative part based on in-depth analysis of student interviews. In this paper we focus on the interviews and investigate students' experiences regarding use of Peer Instruction and the effect of the initial voting session. The analysis of the video material is ongoing and will be presented at a later date. The paper starts with a description of study design and analysis methods followed by a presentation of the results. We conclude with a discussion of our findings; in particular, we discuss the results in light of the recent quantitative studies on Peer Instruction.

\section{Method}

The study was conducted in an introductory physics course for preparatory engineering students. The lectures usually consisted of $2 \times 45 \mathrm{~min}$. sessions generally constructed so that the first $45 \mathrm{~min}$. dealt with new theory while the second focused on practical work, mainly problem solving. Four parallel classes with of a total of seven teachers (three classes used two different teachers) used SRS for eight weeks. One of the authors (K. L. Nielsen) was the teacher of the class with a single teacher. The second author (G. Hansen-Nygård) was present in lectures where SRS was used to function as an observer. Each class consisted of 50-70 students, the majority being male students. The theoretical part of the lectures was traditional teacher-style lectures (using digital blackboards) except that the teacher would present the students with 1-4 quizzes consisting of conceptual multiple choice questions. Each student borrowed an Apple iPod Touch which was used as a voting device. When SRS was used, the iPods were handed out at the beginning of the lecture and collected at the end. SRS was used in two of a total of three lectures each week due to some lectures running parallel timetables. To minimize the amount of variables in our data, all classes used the same set of multiple choice questions. We prepared around 50 concept questions which the teachers used in the course of the study.

In order to investigate the effects of the initial thinking period with Peer Instruction, we also used another method which we called "Classic" as the reference. This method was similar to Peer Instruction apart from the initial voting 
session (and thinking period) being omitted; students started discussing immediately after the question was presented. In both methods, the discussions were concluded with a vote and a teacher explanation. During this project, two classes started with Peer Instruction while the other two started with Classic. After four weeks, we switched the methods in all classes.

In order to get as reliable feedback from the students as possible, we did not emphasize that we were going to compare different methods. The teacher would just give different instructions based on the method used; for instance, to think individually without speaking to their fellow students in the case of the initial voting session of Peer Instruction. In both methods, students were encouraged to discuss the presented question in small groups for 2-4 minutes. The initial thinking period with Peer Instruction usually lasted about 1-2 minutes.

The students were interviewed twice, once after Peer Instruction and once after Classic. One exception was one class which already had experience with SRS and the Classic method. That particular class had already been interviewed about SRS, and therefore was only interviewed once at the end of the 8-week testing period. The interviews were conducted by one of the authors (GHN). The first interview was about three hours and consisted of questions regarding students' experiences with SRS in general. The second interview was shorter (around 60 minutes) and focused directly on the differences between the two methods. Many of the topics and questions in the second interview were created based on student feedback in the first interviews. The student interviews were conducted as focused (semistructured) group interviews, which is recognized as a reliable method of revealing informants' perspectives [27]. There were four groups (one from each class) with four students per group consisting of both male and female students.

The interviews were analyzed using analytical tools from grounded theory. We want to emphasize that we have not conducted a true grounded theory analysis, that is, with theory sampling to achieve theoretical saturation, but rather we have borrowed the analytical tools. These include a threestep coding scheme (line-by-line coding, focused coding, and categorization) adapted from Charmaz $[28,29]$. This method is an appropriate direction for analysis of topics such as personal experiences, opinions, feelings, and attitudes [28]. The first step is to examine each line of data material and code it to define events that appear or are represented $[28,29]$. We relied heavily on "in vivo" codes, that is, using the interviewers own words in the early stages of coding. This was to avoid misinterpretations of students' utterances and assure that we maintained a close relationship between the codes and what expressed by the students. The next phase is to focus on several lines or paragraphs of the interviews (focused coding) where the most significant line-by-line codes are identified. Thus, we are left with a smaller number of codes that give a more accurate description of the data. In the last step, categorization, focused codes are treated more analytical and conceptual [28]. Each focused code is described in detail: its properties, its consequences, how they relate to other focused codes, and conditions under which they arise, is maintained, and changes [29]. This process often led to several focused codes being merged when very close relationships were discovered. In the end we have a small number of categories that describe students' most significant experiences, in this case their experiences of the two SRS-sequences, Peer Instruction, and Classic.

\section{Results}

The analysis of the interviews resulted in three categories: (1) Argumentation and explanation, (2) Peer Instruction: Opportunity for individual thinking, and (3) Seeing the results: Authority of the majority. The first category deals with the students' experiences of generating explanations and presenting arguments in group discussions, and how they perceive explanations and arguments from fellow students (and to some extent the teacher). It is not about the content of the arguments and explanations per se, but rather about the students' own experiences of the process of generating and presenting them and how this relates to their learning. The second category is about thinking without the influence of others and how Peer Instruction gives an opportunity to reflect more deeply upon the questions and forming one's own opinion, resulting in increased participation and confidence during discussion. The last category focuses on seeing the results from the initial vote in Peer Instruction and how a clear majority can influence students' decision-making and the group discussion.

Category 1: Argumentation and Explanation. Learning physics is more than just memorizing formulas. Although memorization is an important part of their learning process, students also emphasize the importance of being able to reflect upon and solve problems, preferably without the help or influence of others (Category 2). However, according to the students, the best confirmation that they have learned physics is when they are able to explain the solution to other students. Then they have to challenge themselves to explore other ways of thinking in order to generate explanations and arguments that will make the solution both convincing and understandable. In addition, explanations from their peers are often easier to understand because students have the same foundation and speak "the same language." Students feel that the teacher is on a "higher level" and often uses complex words and phrases which can make his/her explanation hard to follow.

You have to sort of re-learn it when you are going to explain it to others.

It becomes other words then [when peers explain], because it is like-minded people who repeat what the teacher said in a different way.

According to the students, good group discussions with SRS start with an uncertainty or disagreement about the answer and all students collaborate towards a consensus. 
Different students remember different things, making it important that everyone participates. Also, if a student does not object or ask questions, it can be interpreted as agreement and that he/she understands the arguments being presented. In other words, being passive can result in students not being given enough explanation to understand the solution, and selecting the correct answer does not benefit learning if they have not understood why it is correct.

I think it is important that everyone participates so that they can follow and understand why it is not like this and why it is like this.

If I do not say what I think, then maybe they just expect me to agree with them. And then no-one cares to explain it. So even if I vote the same as them and get the right answer, it does not help if I do not understand it.

When students feel that they understand the question and have a good argument, they are more likely to be active during the discussion and try to convince their fellow students. Being convinced or proven wrong is an important part of their learning. As one student puts it:

I think you remember it better for later if you are proven wrong.

On the other hand, if the students are uncertain about the question or the solution, they are more inclined to be passive and withdraw from the discussion. Another factor that can increase passivity is sitting with students they do not know well. They are afraid of making a fool of themselves when they do not know how their fellow students will react to their arguments. Passivity in group discussions is also prominent if a student in the group is regarded as being skillful or "strong." The arguments and explanations of stronger students are valued higher than those with equal or lesser skills. Students are then more likely to only listen to these explanations rather than try to find out the solution for themselves, often accepting the others' conclusions without fully understanding them.

You are more passive when you are uncertain, because then you listen to what the others say. And it might be the case that you did not understand the question and the alternatives the way you should have, and when the guy next to me says that it is like this and this: "OK, then maybe it is like this then". And then you look at it and "OK, I think this also", so without being certain of the answer I will vote the same.

When we sit and discuss there are certain people in the class you know are very skillful. So if someone in this group talks very loud or a person you know is very skillful says "No, it is B because...", and then they start to talk, then everyone else in the group will just shut up and listen to what that person has to say. Then it becomes like "Yeah, OK. So maybe it is like this", if you are uncertain. Then it is easy that you just listen to the others in the group rather than try and find the answer for yourself.

The results from the voting session can thus give the teacher a "false" image of the level of understanding among the students. Even though the majority of students have voted for the correct answer, it does not mean that the majority have understood why it is correct. Students therefore emphasize the importance of the explanation given by the teacher after group discussions. The teacher should explain thoroughly both the correct and incorrect alternatives. Learning is not only gained by understanding why an alternative is correct. Understanding why an alternative is incorrect can be just as fruitful and often crucial, especially for students who have voted for the incorrect alternative.

Even if the majority has voted correctly, I still think a short explanation is needed. Because the situation can be so that you just voted what the guy next to you thinks is correct and you just follow him. So it is good that we still get a short explanation.

There was one question we sat and discussed which we were absolutely sure was the correct answer. Then it turned out that it was actually wrong, and then I think that it is good that they [the teachers] explain. That they do not just say that "This is correct" and just explain this alternative, but that they go through all the alternatives and explain why they are wrong or show us with illustrations. Because then it is much clearer: "Yes, of course it is like this".

Category 2: Peer Instruction: Opportunity for Individual Thinking. The SRS gives students an opportunity to engage in solving problems in group discussions during lectures. If this is to really benefit their learning, however, students emphasize that it is important that they are able to reflect more deeply upon the problem at hand and struggle with it. Students feel that Peer Instruction, with its initial thinking period, gives them an opportunity to actually involve themselves in the question before discussions. This will not only enhance learning during discussion, it will also make it easier to remember the solution and explanation given by the teacher after the discussion.

Yes, we have enough time to involve ourselves in the question [with Peer Instruction], and that is what's important. That you have thought deeply 
about it. Because it's first then you really have a benefit of the answer.

If you first have pondered over something, and maybe you did not find the solution, and then you get the explanation, then it is much easier to remember it [the solution]. When you first had the opportunity to struggle with something, and then you get the explanation, then you remember much better.

For students to get involved in the questions, they feel that it is very important that they are able to form their own opinion without the influence of others. This can be difficult to achieve when using the Classic method because they go straight into group discussion after the question is presented. They are not given the opportunity to think individually without being "colored" by other students.

I think it was much better [with Peer Instruction], because you are allowed to think for yourself and not having objections from everybody else.

You get a chance to make up your own mind before you get colored by what everybody else thinks.

You do not have time to think before you are influenced by the others' opinions [with Classic].

Students use the initial thinking period with Peer Instruction to construct their own mental image of the problem and an explanation which they can use in the following discussion (Category 1). When using the Classic method, explanations have to be generated during the discussion period (or when the teacher is reading the question), but often students experience that they barely have time to think before someone takes control and starts talking. When these students start to "think out loud", other students will have a difficult time thinking and working out logical arguments (unless they step in and actively participate by uttering their own thoughts). They can quickly be drawn towards the arguments and conclusions of the students taking control and vote the same alternative without having been able to think for themselves and understand the answer.

I think that it blocks your own thoughts if you first have to listen to other people's ideas without having thought about it yourself; that you in a way forget to think for yourself.

With an explanation ready, students feel they have much more to contribute to the discussions. Everyone in the group is more likely to be heard because they can present more convincing arguments for their opinions (Category 1). The group consists of stronger individuals who are more inclined to defend their views when they are given time to think for themselves. This way, both stronger and weaker students can benefit more from the Peer Instruction method since weaker students have greater opportunities to construct and present arguments, while stronger students have a higher probability of having their arguments challenged.

After we have thought by ourselves, we have so much more to say, rather than when we went straight into discussion.

The initial thinking time you have, I think that is great! Then you are able to reflect over what you think so that you have a better basis for participating in the discussion in your group.

I feel that there will always be someone who dominates more, but now everyone had something to bring to the table, and everyone was heard because you had a better explanation for your opinions.

With Peer Instruction the students find using SRS more serious and orderly. When using Classic it can be hard to know, according to the students, when to stop thinking for themselves and start discussing. With Peer Instruction, however, they know that the discussion starts immediately after the initial voting session. It thus becomes easier to focus on what they should do, when they should think for themselves and when they should discuss. There is more time to come to a consensus and find a shared solution that everyone is comfortable with. Since they are likely to have formulated an explanation during the initial voting session, more of the discussion time is used for actual discussion.

The latter was the absolute best, yes, really [Peer Instruction]. It was a little more serious from the start really, because you had to work alone and had thought by yourself first. You put a little more into it than if you went directly to the group discussion, at least I think so. Also you got started at once, you got a better focus.

We also noticed that it was difficult to reach a good explanation [with Classic] that we agreed and where we felt that "Yeah, it must be right." It was not always we were quite there yet, no, because there was such a short time. It was better when we had thought about it beforehand, and we had an explanation ready. So when we started to discuss there was more time to agree, and feel that we had the answer. 
Category 3: Seeing the Results: Authority of the Majority. Students clearly prefer Peer Instruction and experience it as the best method with regard to their own learning. However, the method is not without its weaknesses. After the initial vote the results are shown on a histogram. This last category is about how seeing these results can affect the quality of the discussions and how this in turn affects the students' decision making. If there is a clear majority that has chosen a specific alternative, the discussion can often be guided towards this alternative. It is very likely the students just assume that this alternative is correct and try to work out why it is correct, rather than go through all alternatives to work out what is correct and what is not. With the Classic method they do not see any results before discussion and so every alternative is considered equal when they enter discussion.

You become guided, or misguided, and lose focus of what you are supposed to discuss because so many in the class have voted " $\mathrm{B}$ ".

If you just see that " $B$ " has gotten most of the votes, then you might just end up with trying to explain why " $\mathrm{B}$ " is correct rather than trying to find out what is the right answer.

Because if $80 \%$ have voted for one of the alternatives, then there is a high probability that it is correct, right? So then the discussion is focused on finding out why it is correct. And if we hadn't chosen this [alternative], it would have been better if we did not know about it.

Several students point out that it is not necessarily the majority that has chosen the correct alternative. Despite this, students feel that they still would be very likely to choose the same as the majority no matter what arguments are presented in the discussion, and without necessarily understanding why it is "correct".

If most have voted "B" and you answered " $\mathrm{A}$ ", you're very inclined to answer " $\mathrm{B}$ " however the others argue for or against it.

When students feel very uncertain they simply go for the alternative they perceive as most likely, which in most cases will be equal to the alternative which has got a clear majority of the votes (if any). If they have chosen an alternative with the majority of votes in the initial voting session, students become more confident in their choice, lowering their threshold for presenting arguments (Category 1). Even though they may not have the best arguments for this alternative, the students feel they are likely to be more certain of its correctness and defend their choice. The picture is reversed if their initial vote is in the minority. According to the students, they have to be very confident in their arguments to defend such an alternative.
Interviewer: So the $20 \%$ of students who have voted for alternative " $C$ " might not fight as hard to defend alternative "C" because $80 \%$ have voted alternative "B"?

Everyone: Yes.

Student: It's not even certain that people will admit that they have answered " $\mathrm{C}$ ". It is likely that you will just ask the group "OK, why is it B?" That you just assume that it is " $\mathrm{B}$ " because the majority has voted "B". So then you will just try to explain why this is correct, even though it might not be the correct answer. It might be the case that the majority voted incorrectly.

Seeing a clear majority displayed in the results from the initial vote might have most effect on the group discussion when everyone in the group has answered the same as the majority. The students agree among themselves in the group and the majority of the class agrees with them. Then they are likely to lose interest in the question and talk about something else.

It just wasn't interesting to talk about it then [when they saw the results from the initial vote].

Therefore students feel that it would be much better to not see the results of the initial vote until after the re vote. They find it interesting to see if the class have changed their mind during discussion, so several students point out that the best method would be to use Peer Instruction, but to wait to show the results of the initial vote until after the discussion to minimize "damage" to the discussion. As one student puts it:

If you remove it [the results from the initial vote] there would have been better discussion per person in the class.

\section{Discussion and Conclusion}

We have studied students' experiences of Peer Instruction with and without the initial voting session using focus group interviews and a grounded theory-based analysis. Students value the initial voting session as a means of delving more deeply into the question, generating a mental image of the problem and constructing an explanation with convincing arguments to use in the following discussion. This is consistent with findings of Nicol and Boyle [20]. In order to generate good explanations, students need time to clarify their thoughts and reflect more deeply upon the problem at hand [5]. Without the initial voting session such a process becomes very difficult because they will only be "allowed" to think and reflect until the first student starts to speak or "think aloud." The consequence is often less participation and higher probability of accepting explanations presented by "stronger" students.

Although the students emphasize the need to construct convincing arguments in order to defend their views, they do not necessarily feel this merely to "win" the discussions. A 
simplistic view of argumentation is to view it as a battle where one tries to defeat one's opponent. Duschl and Osborne [5] argue that argumentation is also an exploration to find and fill out holes in one's knowledge. This view is supported by the students. They want to be convinced of the arguments presented, and to be proven wrong can function as a high facilitator of learning as it can challenge their thinking and reveal flaws in their understanding. The initial voting session results in more arguments and ideas being presented during discussion and the students are more likely to come to a consensus.

Another consequence of a greater number of ideas presented at the start of discussion is an increase in the probability of disagreement. Difference is an important part of learning, as Duschl and Osborne [5] stated fittingly: "without difference, there can be no argument, and without argument, there can be no explanation" (p. 53). This is not to say that initial conflict necessarily translates to increased learning. It is also important that the students actively engage in either trying to convince their neighbor or to be convinced, that is, that they state their thoughts and (dis)agreement. Passive compliance and/or insufficient verbalization during group discussion can have a detrimental effect on the learning outcome of discussions [2].

Our research is consistent with the findings of Perez et al. [22] and Brooks and Koretsky [21] that displaying the results of the initial voting session can affect students' decision making and confidence during discussion. As predicted by Perez et al. [22], the students in our research experience that an alternative with a clear majority of the votes becomes a center of focus for the group discussion, although not in a positive sense. Students point out that they will not necessarily try to find out the reason why the majority has chosen one specific alternative; they will automatically assume that it is correct. The histogram becomes an argument in itself, an argument much stronger than those presented in the discussion or through individual reasoning. The focus becomes on finding out why the alternative is correct and not if it is correct.

The bias from seeing the results from the initial voting session was also shown to be stronger for more difficult questions [22]. Although our students do not specify this connection in particular, they do emphasize a stronger influence when they feel uncertain, and it is likely there is a high correlation between the difficulty of the question and the level of uncertainty among the students. By not showing the results prior to discussion, every alternative is initially considered equal. Rather than trying to "force" a solution upon an alternative with a clear majority, students are more likely to evaluate each alternative more thoroughly.

Without a total evaluation of all alternatives, students will be more dependent on the teacher in order to accept the correctness of the alternative, rather than having it come through their own argumentation [5]. This is a prominent feature in novice students [25], and it is therefore not surprising that the students in our research emphasize the importance of the teacher explanations following the discussions. Our students stress the importance of the teacher carefully explaining the correct alternative and why it is correct in order to be convinced of the solution. This is consistent with the findings of Nicol and Boyle [20]. In addition, our students also emphasize the importance of the teacher explaining why the incorrect alternatives are incorrect. If they do not choose the correct alternative, or are not sure of its correctness, they need an explanation to be convinced and fully understand the solution.

Smith et al. [24] argued that there is a synergy effect between peer discussion and the teacher explanation, making the combination facilitate more learning than either on its own. A majority of the students in their study also agreed that the peer discussion made them more prepared for the following explanation. The students' experiences in our study are consistent with these findings in that the students feel that reflecting and struggling with a question makes it easier to remember the following explanation from the teacher. The initial voting session is crucial for this to happen as deeper reflection is difficult to achieve during peer discussion if they do not have time to formulate their thoughts without the influence of others.

In the study by Smith et al. [24], many students even reported frustration when the teacher explanation was excluded when using Peer Instruction. An explanation for this can be that the teacher explanation functions as a closure for the SRS session and also removes any last doubts. Our students feel that they are very seldom 100\% sure about the correctness of the answer, and therefore they need the feedback that they have not only chosen the correct answer, but have also understood the solution correctly. Not receiving this feedback is likely to cause frustration.

In summary, the students in our research experience Peer Instruction as more beneficial to learning when the initial voting session is included, but where the voting results are not shown until after the revote. Our study has shed more light on recent findings on Peer Instruction from the students' point of view. Nevertheless, more research is required to obtain a more complete picture of the effect of the initial voting session; for instance, to verify students' claims of more fruitful discussions, where more arguments are presented. Our ongoing video analysis of students engaged in peer discussion, both with and without the initial voting session, should be able to give more insight to their experiences.

\section{References}

[1] A. A. Gokhale, "Collaborative learning enhances critical thinking," Journal of Technology Education, vol. 7, no. 1, pp. 22-30, 1995.

[2] A. S. Palincsar, "Social constructivist perspectives on teaching and learning," Annual Review of Psychology, vol. 49, pp. 345375, 1998.

[3] M. Prince, "Does active learning work? A review of the research," Journal of Engineering Education, vol. 93, no. 3, pp. 223-231, 2004.

[4] J. K. Knight and M. K. Smith, "Different but equal? How nonmajors and majors approach and learn genetics," CBE Life Sciences Education, vol. 9, no. 1, pp. 34-44, 2010.

[5] R. A. Duschl and J. Osborne, "Supporting and promoting argumentation discourse in science education," Studies in Science Education, vol. 38, no. 1, pp. 39-72, 2002. 
[6] I. Beaty, "Transforming student learning with classroom communication system," Research Bulletin, vol. 3, pp. 2-13, 2004.

[7] S. W. Draper and M. I. Brown, "Increasing interactivity in lectures using an electronic voting system," Journal of Computer Assisted Learning, vol. 20, no. 2, pp. 81-94, 2004.

[8] C. D. Kam and B. Sommer, "Real-time polling technology in a public opinion course," Political Science and Politics, vol. 39, no. 1, pp. 113-117, 2006.

[9] G. Masikunas, A. Panayiotidis, and L. Bruke, "The use of electronic voting systems in lectures within business and marketing: a case study of their impact on student learning," Research in Learning Technology, vol. 15, no. 1, pp. 3-20, 2007.

[10] S. A. J. Stuart, M. I. Brown, and S. W. Draper, "Using an electronic voting system in logic lectures: one practitioner's application," Journal of Computer Assisted Learning, vol. 20, no. 2, pp. 95-102, 2004.

[11] R. J. Dufresne, W. J. Gerace, W. J. Leonard, J. P. Mestre, and L. Wenk, "Classtalk: a classroom communication system for active learning," Journal of Computing in Higher Education, vol. 7, no. 2, pp. 3-47, 1996.

[12] R. R. Hake, "Interactive-engagement versus traditional methods: a six-thousand-student survey of mechanics test data for introductory physics courses," American Journal of Physics, vol. 66, no. 1, pp. 64-74, 1998.

[13] R. H. Hall, H. L. Collier, M. L. Thomas, and M. G. Hilgers, "A student response system for increasing engagement, motivation, and learning in high enrollment lectures," in Proceedings of the Eleventh Americas Conference on Information Systems, Omaha, Neb, USA, August, 2005.

[14] S. J. Pollock, "Transferring transformations: learning gains, student attitudes, and the impacts of multiple instructors in large lecture courses," in Proceedings of the Physics Education Research Conference, vol. 818 of AIP Conference Proceedings, pp. 141-144, Salt Lake City, Utah, USA, August 2005.

[15] S. P. Rao and S. E. DiCarlo, "Peer instruction improves performance on quizzes," Advances in Physiology Education, vol. 24 , no. 1 , pp. 51-55, 2000.

[16] C. H. Crouch and E. Mazur, "Peer Instruction: ten years of experience and results," American Journal of Physics, vol. 69, no. 9, pp. 970-977, 2001.

[17] E. Mazur, Peer Instruction: A User's Manual, Prentice Hall, Upper Saddle River, NJ, USA, 1997.

[18] P. M. Len, "Different reward structures to motivate student interaction with electronic response systems in astronomy," Astronomy Education Review, vol. 5, no. 2, pp. 5-15, 2007.

[19] M. C. James, "The effect of grading incentive on student discourse in peer instruction," American Journal of Physics, vol. 74, no. 8, pp. 689-691, 2006.

[20] D. J. Nicol and J. T. Boyle, "Peer Instruction versus class-wide discussion in large classes: a comparison of two interaction methods in the wired classroom," Studies in Higher Education, vol. 28 , no. 4, pp. 457-473, 2003.

[21] B. J. Brooks and M. D. Koretsky, "The influence of group discussion on students' responses and confidence during peer instruction," Journal of Chemical Education, vol. 88, no. 11, pp. 1477-1484, 2011.

[22] K. E. Perez, E. A. Strauss, N. Downey, A. Galbraith, R. Jeanne, and S. Cooper, "Does displaying the class results affect student discussion during peer instruction?" CBE Life Sciences Education, vol. 9, no. 2, pp. 133-140, 2010.

[23] M. K. Smith, W. B. Wood, W. K. Adams et al., "Why peer discussion improves student performance on in-class concept questions," Science, vol. 323, no. 5910, pp. 122-124, 2009.
[24] M. K. Smith, W. B. Wood, K. Krauter, and J. K. Knight, "Combining peer discussion with instructor explanation increases student learning from in-class concept questions," CBE Life Sciences Education, vol. 10, no. 1, pp. 55-63, 2011.

[25] J. K. Knight and W. B. Wood, "Teaching more by lecturing less," Cell Biology Education, vol. 4, no. 4, pp. 298-310, 2005.

[26] J. E. Caldwell, "Clickers in the large classroom: current research and best-practice tips," CBE Life Sciences Education, vol. 6, no. 1, pp. 9-20, 2007.

[27] A. Johannessen, P. A. Tufte, and L. Kristoffersen, Introduksjon til Samfunnsvitenskapelig Metode, Abstrakt Forlag AS, Oslo, Norway, 2004.

[28] K. Charmaz, "Grounded theory," in Rethinking Methods in Psychology, J. A. Smith, R. Harre, L. Langenhove et al., Eds., pp. 27-49, Sage, London,UK, 2001.

[29] K. Charmaz, "Grounded theory," in Qualitative Psychology; A Practical Guide to Research Methods, J. A. Smith, Ed., pp. 81110, Sage, London, UK, 2003. 

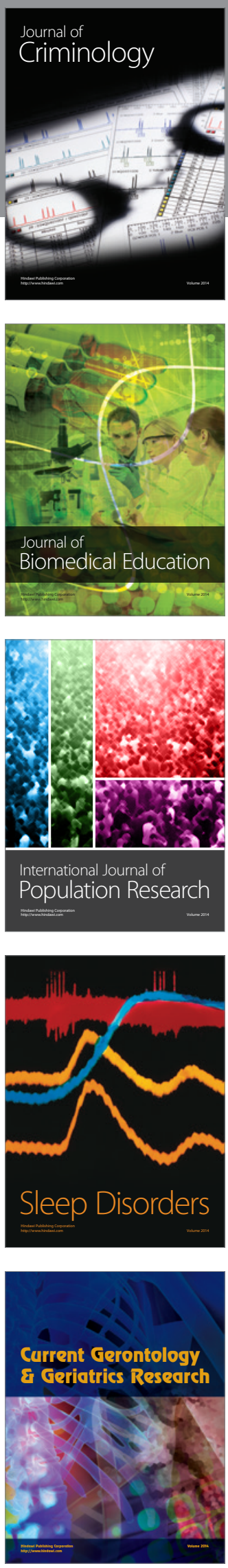
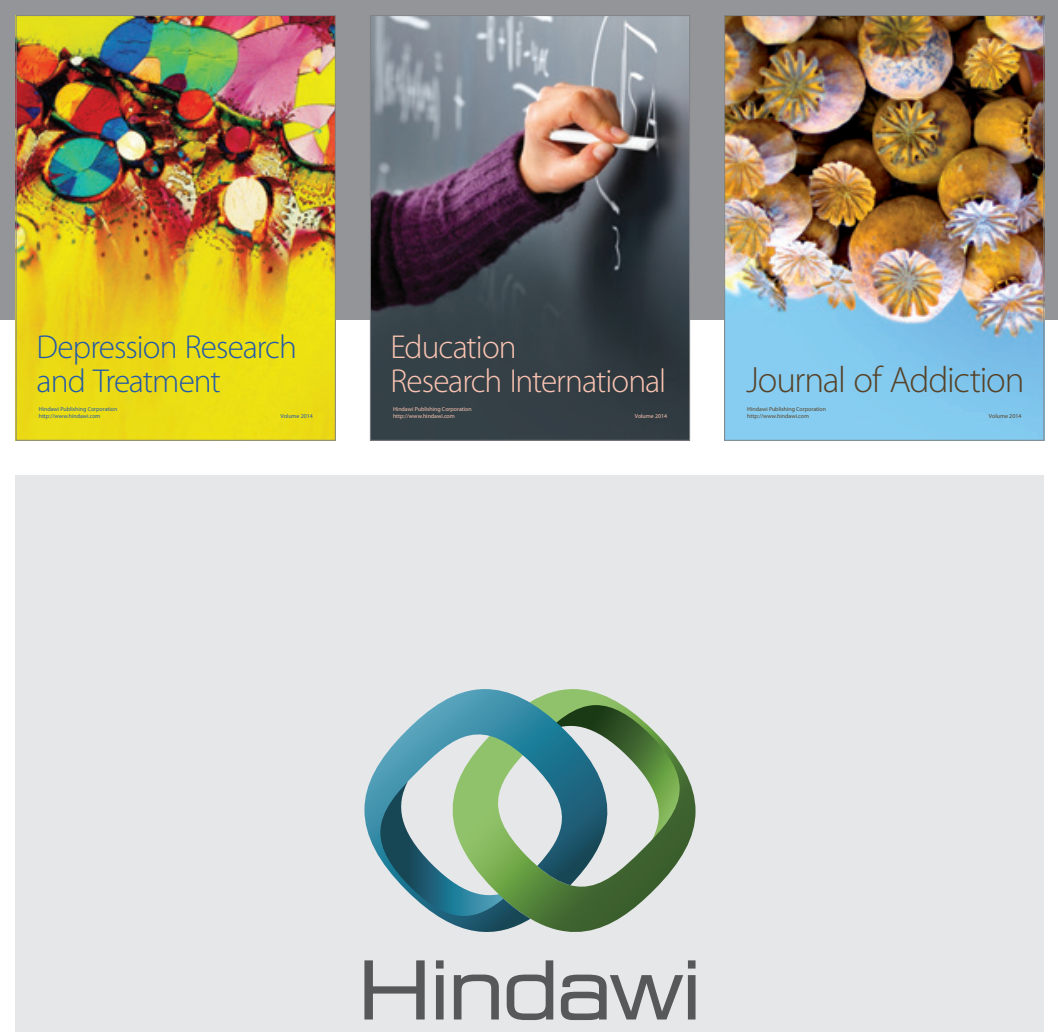

Submit your manuscripts at

http://www.hindawi.com

Child Development Research
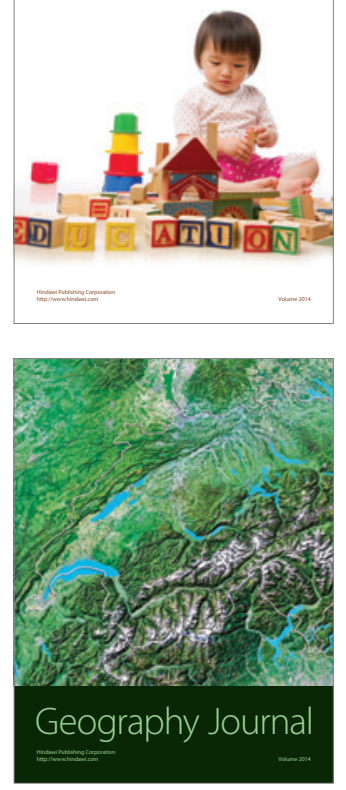

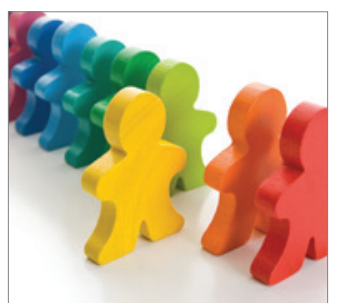

Autism

Research and Treatment
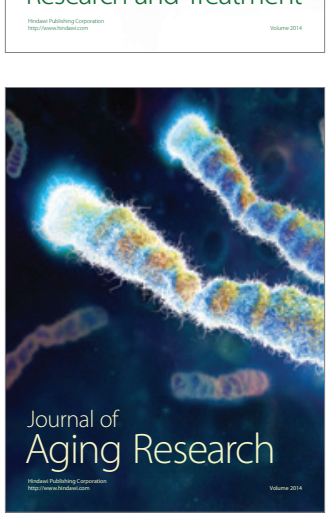
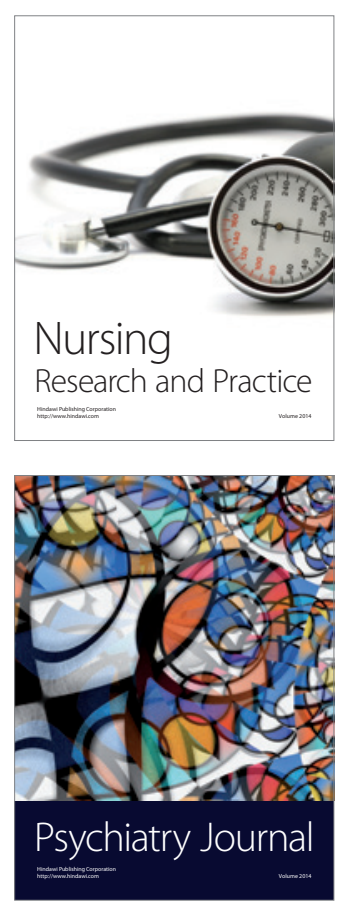
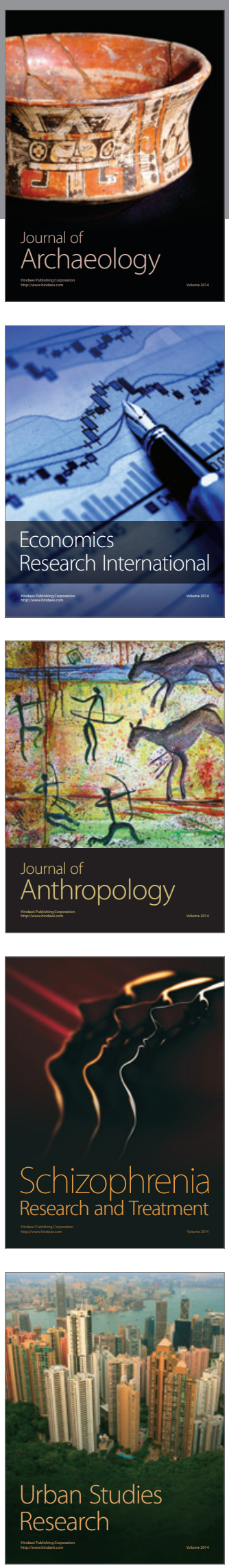